\title{
Tyrosine Hydroxylase and DOPA Decarboxylase Gene Variants in Personality Traits
}

\author{
Ina Giegling ${ }^{a}$ Daniel Moreno-De-Luca ${ }^{b}$ Raffaella Calati ${ }^{b}$ \\ Annette M. Hartmann ${ }^{a}$ Hans-Jürgen Möller ${ }^{a}$ Diana De Ronchib ${ }^{b}$ Dan Rujescu ${ }^{a}$ \\ Alessandro Serretti ${ }^{b}$ \\ ${ }^{a}$ Department of Psychiatry, Ludwig Maximilian University, Munich, Germany; ${ }^{b}$ Institute of Psychiatry, \\ University of Bologna, Bologna, Italy
}

\section{Key Words}

Tyrosine hydroxylase $\cdot$ DOPA decarboxylase $\cdot$ Personality

traits - Genetics - Dopaminergic system

\begin{abstract}
Personality influences several characteristics of normal and pathologic behaviors and it is associated with neurotransmitter systems that are under genetic control. The dopaminergic system has been proposed to play a role in the modulation of personality traits. In the present study, variants of the tyrosine hydroxylase (TH) and DOPA decarboxylase (DDC) genes (for TH: rs3842727, rs6356; for DDC: rs1451371, rs1470750, rs998850) were investigated in 111 suicide attempters and 289 healthy subjects to assess the involvement of the dopaminergic synthesis pathway in personality traits. No strong evidence was found for the associations between personality and TH or DDC in overall tests. An interaction effect of genotype and diagnosis was present, with $\mathrm{TH}$ and DDC SNPs having a greater effect on the respective personality dimensions in the group of suicide attempters. Because of the risk of false positives, these findings should be inter-
\end{abstract}

\section{KARGER}

Fax +41613061234 E-Mail karger@karger.ch www.karger.com (c) 2009 S. Karger AG, Basel

0302-282X/09/0591-0023\$26.00/0

Accessible online at:

www.karger.com/nps preted with highest caution. Direct replication attempts within independent groups of suicide attempters will help to resolve this question.

Copyright $\odot 2009$ S. Karger AG, Basel

\section{Introduction}

Personality, defined as the dynamic organization of the psychobiological systems that modulate adaptation to experience, influences several characteristics of normal and pathological behaviors [1-6]. Temperament traits, which are predominantly stable throughout life and not markedly influenced by the environment, are the most heritable component of personality and have been associated with neurotransmitter systems $[2,7]$. Several studies have been performed with the aim of detecting gene variants associated with specific temperament traits, but results have been conflicting [8-11]. The relationship between the dopaminergic system and temperament traits has been proposed and thoroughly studied through gene variants in the dopamine receptors $[9,10,12,13]$; never- 
theless, results have not always been reproducible [14, 15] and other genes in the dopaminergic system should be considered.

Genes involved in the pathway for dopamine synthesis appear to be interesting candidates for personality studies. Efforts have been made to assess dopamine levels in the central nervous system, either by directly measuring them or through its metabolites, and correlate them to specific personality traits and behaviors. Presynaptic dopamine synthesis capacity was shown to play a role in the regulation of anxiety in healthy adults [16], while dopamine levels in the striatum of rats have been negatively correlated with harm avoidance [17]. On the other hand, cerebrospinal fluid levels of homovanillic acid, an indicator of dopaminergic function, showed a trend of association with novelty seeking [18], although this finding did not reach statistical significance in this or other studies [19]. These results are in agreement with the proposed role of dopamine synthesis pathway in personality traits but require further investigation to be confirmed.

Dopamine is synthesized from the amino acid tyrosine undergoing two steps, the first one producing DOPA by the action of tyrosine hydroxylase $(\mathrm{TH})$, the rate-limiting enzyme in catecholamine synthesis, and the second one from DOPA to dopamine through the DOPA decarboxylase (DDC) enzyme. Both steps could therefore modulate the system.

The TH gene, which codes for TH, is located on chromosome 11p15; it contains 13 primary exons and it spans along approximately $8 \mathrm{~kb}$. It encodes for four different mRNAs through alternative splicing, two of which (both with exon 2 excluded) are expressed in the brain [20,21]. A functional tetranucleotide polymorphism [(TCAT)n] has been described in the first intron of the TH gene [22, 23], defining five alleles, named T6, T7, T8, T9 and T10. These variants have been suggested to regulate the turnover rate of catecholamines, apparently correlating with behavioral differences; higher scores in the neuroticism facets among T8 carriers and higher conscientiousness scores as well as lower openness scores have been described in women carrying the T6/T10 phenotype [24]. However, posterior studies have been unable to confirm this association [25], showing instead a relation between the T9 allele and extraversion.

DDC is encoded by the DDC gene, located on chromosome $7 \mathrm{p} 11$, and consists of 15 exons spanning more than $100 \mathrm{~kb}$ [26]. Variants of the DDC gene have not been investigated regarding personality traits.
Given that the involvement of the dopamine synthesis pathway has not been consistently related to personality traits and that results are still conflicting, we investigated if polymorphisms in the TH and DDC genes are associated with specific personality traits assessed by the Temperament and Character Inventory (TCI). For that purpose, we investigated a set of markers in the $\mathrm{TH}$ (rs3842727, rs6356) and DDC (rs1451371, rs1470750, rs998850) genes in 111 suicide attempters and 289 healthy subjects.

\section{Materials and Methods}

\section{Suicide Attempters}

The recruitment of suicide attempters was carried out among patients consecutively referred to general psychiatric wards of the Department of Psychiatry, Ludwig-Maximilian University, $\mathrm{Mu}-$ nich, Germany. The sample has been published for investigations into other gene variants $[27,28]$. Systematic information on suicide attempts was obtained from repeated interviews with the patients, all available medical records and the Basic Documentation for Suicidal Behavior [29], in order to discriminate between suicide attempts and other forms of self-harming behaviors and accidents. Only patients of German descent (i.e., both parents were German) with at least one clear-cut suicide attempt were included.

Suicide attempts were classified as violent or nonviolent according to the method used and the severity of the attempt. Patients with a history of a violent suicide attempt were classified as violent regardless of the method used for the most recent attempt. The German version of the Intent Score Scale [30] was also used to define impulsive and nonimpulsive suicidal behavior. If the patient manifested not having had suicide-related thoughts before the attempt, the impulsive attempt was classified as spontaneous. Current and lifetime diagnoses of mental disorders were assessed close to discharge by applying the Structured Clinical Interview for DSM-IV (SCID-I) [31]. Patients with severe general medical condition or with dementia were excluded. A total of 111 suicide attempters (43 males and 68 females; males: $38.7 \%$ ) were included in the study. Their mean age was $39.2 \pm 13.6$ years (range: $18-73$ ). DSM-IV lifetime diagnoses of mental disorders among the patients were as follows: affective spectrum $(n=76 ; 68.5 \%)$, schizophrenia spectrum $(\mathrm{n}=17 ; 15.3 \%)$ and borderline personality disorder $(n=18 ; 16.2 \%)$. The consent rate of patients was about $90 \%$. Written informed consent was obtained from all subjects after a detailed and extensive description of the study, which was approved by the local ethics committee and carried out in accordance with the ethical standards laid down in the Declaration of Helsinki.

Healthy Individuals

Unrelated volunteers of German descent were randomly selected from the general population of Munich, Germany, and contacted by mail. To include only subjects without a personal or family history of neuropsychiatric disorders, a screening was performed before enrolment in the study. First, subjects who re- 
sponded were initially screened by phone. Detailed medical and psychiatric histories were assessed for both themselves and their first-degree relatives by using systematic forms. Second, they were invited to a comprehensive interview (SCID-I and SCID-II) [31, 32].

Psychiatric diagnoses among their first-degree relatives were assessed using the Family History Assessment Module [33]. Subjects with relevant somatic diseases or a lifetime history of any axis I or II psychiatric disorders or suicidal behavior were excluded. Subjects who had first-degree relatives with a lifetime history of a mental disorder or suicidal behavior were also excluded. Finally, 289 subjects (123 males, 166 females; males: 42.6\%) were included. Their mean age was $45.2 \pm 14.9$ years (range: $19-79$ ). The consent rate of controls was about $50 \%$.

\section{Temperament and Character Inventory}

The TCI is a 240 -item tool to assess individual differences in the basic dimensions of the Cloninger biosocial model of personality [2]. The scores have been calculated according to the manual [2], adding up the values of the items corresponding to each dimension. These dimensions comprise harm avoidance, novelty seeking, reward dependence and persistence as temperament scales and self-directedness, cooperativeness and self-transcendence as character scales.

\section{Genotyping}

TH rs3842727, rs6356 and DDC rs1451371, rs1470750, rs998850 were genotyped by Illumina (Illumina, Inc., San Diego, Calif., USA) with their Integrated Bead Array System. Additionally, 23 SNPs in genes spanning all chromosomes were genotyped as genomic controls (rs2006727; rs586726; rs724529; rs206847; rs1868155; rs2009602; rs1383628; rs876635; rs1367828; rs2076940; rs2025557; rs1993181; rs2168213; rs948184; rs2227973; rs1713449; rs2295152; rs1800404; rs1469122; rs731835; rs418251; rs725493; rs1555048). These genes have been selected based on the low a priori probability of involvement in behavioral traits and phenotypes. We supplied Illumina with bar-coded DNA microliter plates containing the DNA quantified with PicoGreen to be at 100 $\mathrm{ng} / \mu \mathrm{l}$ and Illumina delivered genotypes with a quality score calculated by proprietary Illumina algorithms.

\section{Statistical Analyses}

Sociodemographic parameters between the tested groups were compared using $\chi^{2}$ and t tests. The linkage disequilibrium map and the assessment of the Hardy-Weinberg equilibrium were performed using Haploview 3.2 [34]. To compare the TCI scores for each SNP, a separate two-factor multivariate analysis of covariance (MANCOVA) was computed for controls and suicide attempters integrating the 7 TCI subscales as well as the 2 factors genotype and gender controlled for the covariates age and educational level (low, middle, high). MANCOVA was followed by univariate analysis. We used the statistics environment 'R' (http://www.Rproject.org), package 'haplo.score' for haplotype analyses. Sex, age, education and diagnosis were added as covariates. The expectation-maximization algorithm infers haplotypes and calculates maximum likelihood frequency estimates. Single haplotype significance and odds ratios were calculated as well as global significance. Permutation (10,000 permutations) was also performed to estimate the global significance of the results for haplotype analyses to validate the expectation- maximization values. We conservatively calculated the power of our sample with an alpha level of 0.007 (0.05 divided by 7 TCI factors).

With these parameters we had sufficient power on the control sample $(0.80)$ to detect medium effect size $(\mathrm{d}=0.24)$ between the 2 main genotypes, which, for example, corresponds to 1.23 points on harm avoidance scores (TCI) [35]. The other sample had lower power given the reduced sample size (data not shown). For haplotype analysis we had a similar power $[36,37]$

\section{Results}

\section{Comparison of Demographic and Clinical Data among Groups}

Suicide attempters and healthy individuals were not significantly different regarding gender $(p=0.49)$ and education ( $\mathrm{p}=0.12$ ), but patients were significantly younger than controls $(\mathrm{t}=3.7 ; \mathrm{p}>0.001)$. There was a significant difference in TCI scores between suicide attempters and healthy individuals as previously reported [38].

\section{Tyrosine Hydroxylase}

Markers were in Hardy Weinberg equilibrium (rs3842727: $\mathrm{p}=0.38$; rs6356: $\mathrm{p}=0.72$ ). Association with suicide has previously been reported [39]. MANCOVA allowed us to observe an effect of rs3842727 on cooperativeness scores $(F=31.9$; d.f. $=2,392 ; \mathrm{p}=0.0003)$.

Analyzing separately healthy individuals and suicidal patients, in healthy individuals no association was found, while in suicide attempters, the effect of rs3842727 remained marginally significant on cooperativeness scores $(\mathrm{F}=5.9$; d.f. $=2,106 ; \mathrm{p}=0.003)$. Markers were in strong linkage disequilibrium. Overall, haplotypes were not significantly associated with personality scores (global $\mathrm{p}=$ 0.14 , simulated $\mathrm{p}=0.09$ ).

\section{DOPA Decarboxylase}

All markers were in Hardy-Weinberg equilibrium (rs1451371: $\mathrm{p}=0.18 ; \mathrm{rs1470750:} \mathrm{p}=0.13$; $r$ 998850: $\mathrm{p}=$ 0.10). Association with suicide has previously been reported [39]. Rs1470750 showed a marginal effect on selfdirectedness $(\mathrm{F}=6.36$; d.f. $=2,386 ; \mathrm{p}=0.002)$ and selftranscendence $(F=5.07 ;$ d.f. $=2,386 ; \mathrm{p}=0.007)$. Rs 998850 was associated with self-directedness $(\mathrm{F}=11.38$; d.f. $=$ $2,386 ; p=0.000016)$; however, the effect of the marker on self-directedness was significantly dependent on the affected status and sex (interaction: $F=8.1$; d.f. $=2,384$; $\mathrm{p}=0.0004$ ), in fact self-directedness scores were lower in male suicide attempters carrying the G/G genotype (only 
7 subjects). No association was found on rs1451371 SNP. Analyzing separately healthy individuals and suicide attempters, DDC variants did not show significant associations with any TCI dimension. Markers were in strong linkage disequilibrium. Haplotype analyses did not show any association with TCI scores (all $\mathrm{p}$ values $>0.01$ ).

\section{Discussion}

The purpose of this study was to establish if variants in the TH and DDC genes, which define the pathway for dopamine synthesis, were related with specific temperament traits in a sample of suicide attempters and healthy individuals, in order to better characterize the molecular underpinnings of personality.

As we previously reported [39], we found no association between these SNPs in the TH and DDC genes and suicidal behavior. However, it is interesting that an interaction effect of genotype and diagnosis was present, with $\mathrm{TH}$ and DDC SNPs having a greater effect on the respective personality dimensions in the group of suicide attempters. Provided that the observed associations are not false-positive findings, this suggests that other genetic and/or environmental factors may operate in patients and are less pronounced in healthy volunteers. On the other hand, the use of a conservative threshold for statistical significance does not preclude the possibility of observing false-positive results, and these findings should be interpreted with highest caution. Direct replication attempts within independent groups of suicide attempters will help to resolve this question.

The functional polymorphism rs6356 defines a V/M variation at position 2065 in the third exon, which could lead to differences in the protein structure with related changes in its functionality. The use of intermediate phenotypes proves to be an interesting tool to address this issue [40], where the measurement of dopamine levels could provide a quantitative approach to study the effect of these variants on, for example, the rate of dopamine synthesis. Although this strategy also has limitations, since the level of the neurotransmitter depends not only on the rate of synthesis, but also on the rate of catalysis, it can be applied by analyzing functional variants on the genes which control both the synthetic and catabolic pathways: TH, COMT and MAO-A [41]. Tochigi et al. [42] found that, when analyzed together, TH, COMT and $\mathrm{MAO}-\mathrm{A}$ functional variants may provide evidence for the association between metabolic change of catecholamines and personality traits, which may be due to the additive effect of the three genes.

Our study has some limitations: neither the promoter nor the $5^{\prime}$ region of the $\mathrm{TH}$ gene, previously considered regarding personality traits $[24,25]$, were covered. The promoter and the $5^{\prime}$ region were not investigated in the DDC gene either, and the variants studied were all intronic, resulting in findings based on noncoding sequences only. Moreover, gene-gene interactions between the synthetic and catabolic dopaminergic pathways were not investigated. A possible source of stratification bias is ethnic origin, but our sample was composed of subjects from Germany with local antecedents for at least two generations. The German population is considered to be genetically homogeneous [43] and the genomic control SNPs [44] confirmed this hypothesis. Moreover, the large number of comparisons may lead to type I errors (cases vs. controls, victims vs. attempts, aggression, anger, violence, impulsivity, haplotypes). Also the use of haplotypes in case-control studies has been questioned [45]. Finally, a number of factors other than hereditary, which are quite difficult to include in research studies, affect temperament traits [46].

In conclusion, our study does not support a major involvement of the studied SNPs of TH or DDC in personality traits. Further research is required for both $\mathrm{TH}$ and DDC, particularly considering that, to our knowledge, this is the first time that the DDC gene has been studied regarding personality traits.

\section{References}

1 Bratko D, Butkovic A: Stability of genetic and environmental effects from adolescence to young adulthood: results of Croatian longitudinal twin study of personality. Twin Res Hum Genet 2007;10:151-157.

2 Cloninger CR, Przybeck TR, Svrakic DM, Wetzel RD: The Temperament and Character Inventory (TCI): A Guide to Its Development and Use. St Louis, Center for Psychobiology of Personality Washington University, 1994.
3 Klein M, Kupfer D, Shea T: Personality and Depression. New York, Guilford Press, 1993.

4 Bienvenu OJ, Stein MB: Personality and anxiety disorders: a review. J Personal Disord 2003;17:139-151.

5 Steiger H, Bruce KR: Phenotypes, endophenotypes, and genotypes in bulimia spectrum eating disorders. Can J Psychiatry 2007;52: $220-227$. 
6 Grucza RA, Przybeck TR, Cloninger CR: Personality as a mediator of demographic risk factors for suicide attempts in a community sample. Compr Psychiatry 2005;46:214222.

7 Cloninger CR, Adolfsson R, Svrakic NM: Mapping genes for human personality. Nat Genet 1996;12:3-4

8 Van Gestel S, Van Broeckhoven C: Genetics of personality: are we making progress? Mol Psychiatry 2003;8:840-852.

9 Noblett KL, Coccaro EF: Molecular genetics of personality. Curr Psychiatry Rep 2005;7: 73-80.

10 Ebstein RP: The molecular genetic architecture of human personality: beyond self-report questionnaires. Mol Psychiatry 2006; 11:427-445.

11 Serretti A, Calati R, Ferrari B, De Ronchi D: Personality and genetics. Curr Psychiatry Rev 2007;3:147-159.

12 Serretti A, Mandelli L, Lorenzi C, Landoni S, Calati R, Insacco C, Cloninger CR: Temperament and character in mood disorders: influence of DRD4, SERTPR, TPH and MAO-A polymorphisms. Neuropsychobiology 2006;53:9-16.

13 Savitz JB, Ramesar RS: Genetic variants implicated in personality: a review of the more promising candidates. Am J Med Genet B Neuropsychiatr Genet 2004;131:20-32.

14 Kim SJ, Kim YS, Kim CH, Lee HS: Lack of association between polymorphisms of the dopamine receptor $\mathrm{D}_{4}$ and dopamine transporter genes and personality traits in a Korean population. Yonsei Med J 2006;47:787792.

15 Jonsson EG, Nothen MM, Gustavsson JP, Neidt H, Brene S, Tylec A, Propping P, Sedvall GC: Lack of evidence for allelic association between personality traits and the dopamine $\mathrm{D}_{4}$ receptor gene polymorphisms. Am J Psychiatry 1997;154:697-699.

16 Laakso A, Wallius E, Kajander J, Bergman J, Eskola O, Solin O, Ilonen T, Salokangas RK, Syvalahti E, Hietala J: Personality traits and striatal dopamine synthesis capacity in healthy subjects. Am J Psychiatry 2003;160: 904-910.

17 Ray J, Hansen S, Waters N: Links between temperamental dimensions and brain monoamines in the rat. Behav Neurosci 2006;120: 85-92.

18 Mitropoulou V, Trestman RL, New AS, Flory JD, Silverman JM, Siever LJ: Neurobiologic function and temperament in subjects with personality disorders. CNS Spectr 2003;8: 725-730.

19 Limson R, Goldman D, Roy A, Lamparski D, Ravitz B, Adinoff B, Linnoila M: Personality and cerebrospinal fluid monoamine metabolites in alcoholics and controls. Arch Gen Psychiatry 1991;48:437-441.
20 Persson ML, Wasserman D, Geijer T, Jonsson EG, Terenius L: Tyrosine hydroxylase allelic distribution in suicide attempters. Psychiatry Res 1997;72:73-80.

21 O’Malley KL, Anhalt MJ, Martin BM, Kelsoe JR, Winfield SL, Ginns EI: Isolation and characterization of the human tyrosine hydroxylase gene: identification of $5^{\prime}$ alternative splice sites responsible for multiple mRNAs. Biochemistry 1987;26:6910-6914.

22 Polymeropoulos MH, Xiao H, Rath DS, Merril CR: Tetranucleotide repeat polymorphism at the human tyrosine hydroxylase gene (TH). Nucleic Acids Res 1991;19:3753.

23 Meloni R, Albanese V, Ravassard P, Treilhou F, Mallet J: A tetranucleotide polymorphic microsatellite, located in the first intron of the tyrosine hydroxylase gene, acts as a transcription regulatory element in vitro. Hum Mol Genet 1998;7:423-428.

24 Persson ML, Wasserman D, Jonsson EG Bergman H, Terenius L, Gyllander A, Neiman J, Geijer T: Search for the influence of the tyrosine hydroxylase (TCAT)(n) repeat polymorphism on personality traits. Psychiatry Res 2000;95:1-8.

25 Hibino H, Tochigi M, Otowa T, Kato N, Sasaki T: No association of DRD2, DRD3, and tyrosine hydroxylase gene polymorphisms with personality traits in the Japanese population. Behav Brain Funct 2006;2:32.

26 Sumi-Ichinose C, Ichinose H, Takahashi E, Hori T, Nagatsu T: Molecular cloning of genomic DNA and chromosomal assignment of the gene for human aromatic L-amino acid decarboxylase, the enzyme for catecholamine and serotonin biosynthesis. Biochemistry 1992;31:2229-2238.

27 Rujescu D, Giegling I, Sato T, Moeller HJ: A polymorphism in the promoter of the serotonin transporter gene is not associated with suicidal behavior. Psychiatr Genet 2001;11: 169-172.

28 Serretti A, Mandelli L, Giegling I, Schneider B, Hartmann AM, Schnabel A, Maurer K, Moller HJ, Rujescu D: HTR2C and HTR1A gene variants in German and Italian suicide attempters and completers. Am J Med Genet B Neuropsychiatr Genet 2007;144B:291299.

29 Kulessa C, Möller H, Schaller S, Schmidtke A, Torhorst A, Wächtler C, Wechsung P, Wedler H: Basisdokumentation suizidalen Verhaltens. Göttingen, Hogrefe, 1987.

30 Pierce DW: The predictive validation of a suicide intent scale: a five year follow-up. $\mathrm{Br}$ J Psychiatry 1981;139:391-396.

31 First MB, Spitzer RL, Gibbon M, Williams JB: Structured Clinical Interview for DSMIV Axis I Disorders - Patient Edition (SCIDI/P, Version 2.0). New York, Biometrics Research Department, New York State Psychiatric Institute, 1995.
32 First MB, Spitzer RL, Gibbon M, Williams BW, Benjamin L: Structured Clinical Interview for DSM-IV Axis II Personality Disorders (SCID-II). New York, Biometrics Research Department, New York State Psychiatric Institute, 1990.

33 Rice JP, Reich T, Bucholz KK, Neuman RJ, Fishman R, Rochberg N, Hesselbrock VM, Nurnberger JI Jr, Schuckit MA, Begleiter H: Comparison of direct interview and family history diagnoses of alcohol dependence. Alcohol Clin Exp Res 1995;19:1018-1023.

34 Barrett JC, Fry B, Maller J, Daly MJ: Haploview: analysis and visualization of $\mathrm{LD}$ and haplotype maps. Bioinformatics 2005;21: 263-265.

35 Cohen J: Statistical Power Analysis for the Behavioral Sciences. Hillsdale, Erlbaum, 1988.

36 Purcell S, Sham P: Genetic Power Calculator. London, Social, Genetic \& Developmental Research Centre, 2001.

37 Purcell S, Cherny SS, Sham P: Genetic Power Calculator: design of linkage and association genetic mapping studies of complex traits. Bioinformatics 2003;19:149-150.

38 Calati R, Giegling I, Rujescu D, Hartmann AM, Moller HJ, De Ronchi D, Serretti A: Temperament and character of suicide attempters. J Psychiatr Res 2008;42:938-945.

39 Giegling I, Moreno-De-Luca D, Rujescu D, Schneider B, Hartmann AM, Schnabel A, Maurer K, Moller HJ, Serretti A: Dopa decarboxylase and tyrosine hydroxylase gene variants in suicidal behavior. Am J Med Genet B Neuropsychiatr Genet 2008;147: 308-315.

40 Meyer-Lindenberg A, Weinberger D: Intermediate phenotypes and genetic mechanisms of psychiatric disorders. Nature reviews. Neuroscience 2006:818-827.

41 Netter P: Dopamine challenge tests as an indicator of psychological traits. Hum Psychopharmacol 2006;21:91-99.

42 Tochigi M, Otowa T, Hibino H, Kato C, Otani T, Umekage T, Utsumi T, Kato N, Sasaki T: Combined analysis of association between personality traits and three functional polymorphisms in the tyrosine hydroxylase, monoamine oxidase $\mathrm{A}$, and catechol-Omethyltransferase genes. Neurosci Res 2006; 54:180-185

43 Cavalli Sforza L: The History and Geography of Human Genes. Princeton, Princeton University Press, 1994.

44 Pritchard JK, Rosenberg NA: Use of unlinked genetic markers to detect population stratification in association studies. Am J Hum Genet 1999;65:220-228.

45 Curtis D, Sham PC: Estimated haplotype counts from case-control samples cannot be treated as observed counts. Am J Hum Genet 2006;78:729-730.

46 Saudino KJ: Behavioral genetics and child temperament. J Dev Behav Pediatr 2005;26: 214-223. 